\title{
Engineering geminivirus resistance in Jatropha curcus
}

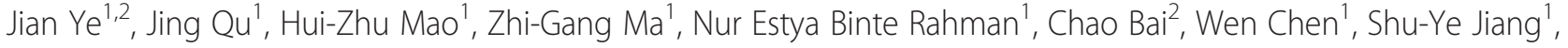 \\ Srinivasan Ramachandran ${ }^{1}$ and Nam-Hai Chua ${ }^{3^{*}}$
}

\begin{abstract}
Background: Jatropha curcus is a good candidate plant for biodiesel production in tropical and subtropical regions. However, J. curcus is susceptible to the geminivirus Indian cassava mosaic virus (ICMV), and frequent viral disease outbreaks severely limit productivity. Therefore the development of J. curcus to carry on durable virus resistance remains crucial and poses a major biotechnological challenge.

Results: We generated transgenic J. curcus plants expressing a hairpin, double-stranded (ds) RNA with sequences homologous to five key genes of ICMV-Dha strain DNA-A, which silences sequence-related viral genes thereby conferring ICMV resistance. Two rounds of virus inoculation were conducted via vacuum infiltration of ICMV-Dha. The durability and heritability of resistance conferred by the dsRNA was further tested to ascertain that T1 progeny transgenic plants were resistant to the ICMV-SG strain, which shared $94.5 \%$ nucleotides identity with the ICMV-Dha strain. Quantitative PCR analysis showed that resistant transgenic lines had no detectable virus.
\end{abstract}

Conclusions: In this study we developed transgenic J. curcus plants to include a resistance to prevailing geminiviruses in Asia. These virus-resistant transgenic J. curcus plants can be used in various Jatropha breeding programs.

Keywords: Biodiesel, Indian cassava mosaic virus, Jatropha curcus, Virus resistance, Transgenic

\section{Background}

Jatropha curcas, a small woody plant belonging to the Euphorbiaceae family, is a non-food oil seed crop mainly grown in the tropical and subtropical regions. This plant possesses several traits render this woody plant suitable for biodiesel feedstock production. It is easy to propagate and grows rapidly. It has a short gestation period, low seed cost and high oil content. Moreover, the ability of $J$. curcus to thrive on degraded soil and its wide adaptability to different growth conditions allows the use of marginal or non-arable wasteland for the application of this plant on an industrial scale. However, the productivity of $J$. curcus in the field is limited by the occurrence of Jatropha curcas mosaic disease (JcMD) [1-3]. The disease incidence is particularly significant in the Indian subcontinent; about $25 \%$ in northern India [1] and up to $47 \%$ in southern India [2].

\footnotetext{
* Correspondence: chua@mail.rockefeller.edu

${ }^{3}$ Laboratory of Plant Molecular Biology, Rockefeller University, 1230 York

Avenue, New York, NY 10021, USA

Full list of author information is available at the end of the article
}

We have previously reported the first full-length genome sequence of one geminivirus, a strain of Indian cassava mosaic virus (ICMV-Dha), as the causative pathogen of JcMD found in Southern India [3]. Following our report, three other related geminiviruses were isolated from Jatropha plants in Africa and South Asia [4-6]. Recently, we reported another highly pathogenic ICMV Singapore strain as the causative agent for JcMD in South-east Asia which shares a $94.5 \%$ identity with ICMV-Dha [7]. The recurrent identification of ICMV as an epidemic viral pathogen in various Jatropha plantations prompted us to investigate the biology of the virus in more detail.

Geminiviruses, which are single-stranded DNA viruses infecting a range of economically important crop species (such as cassava, maize, cotton and tomato) in tropical and subtropical regions, have become a major threat to world agriculture in the past decade [8]. Based on genome organization, insect vector and host range, the family Geminiviridae can be classified into four genera: Begomovirus, Mastrevirus, Curtovirus and Topocuvirus. So far, all five Jatropha viral pathogens belong to one genera: 
Begomovirus. Most of these viruses contain two genomic components termed DNA-A and DNA-B (approximately 2.7 to $3.0 \mathrm{~kb}$ ) and they are all exclusively transmitted via the whitefly, Bemisia tabaci. The virus DNA-A-positive strand encodes the coat protein (CP/AV1) involved in the encapsidation of viral DNA, virus movement and viral transmission by $B$. tabaci). Among other encoded proteins, the replication associated-protein (Rep) AC1 is absolutely required for the replication of both genomic components. The transcriptional activator protein (TrAP) AC2 is needed for transcriptional activation of viral gene transcription and plant host gene expression. The replication enhancer protein (Ren) AC3 greatly enhances viral DNA accumulation by interacting with Rep/AC1. Another viral protein, AC4, acts as a gene-silencing suppressor to compromise the host defense system. All these five genes are essential for the virus life cycle and pathogenesis [8].

Because of the capacity of geminiviruses to evolve rapidly by mutation, recombination and pseudo-recombination, the development of plants with durable virus resistance continues to be a major challenge. One strategy involves genetic crossing of resistant and susceptible Jatropha germplasms. This strategy has the advantage that segregation patterns can be clearly observed between resistant and susceptible lines [9]. However, germplasm-mediated resistance via crossbreeding is time-consuming and requires a large number of progeny plants (large-scale field tests) to ascertain segregation patterns in future generations [9]. Therefore, transgenic technology has been considered as the method of choice for improving the virus resistance of J. curcus. Recently, we and other groups have established transformation platforms which facilitate the transfer of foreign genes into the J. curcus genome [10-13], and we have used this method to produce virus-resistant transgenic J. curcus.

A major strategy to produce transgenic plants with virus resistance is based on the concept of pathogenderived resistance (PDR) in which the transgene is derived from viral sequences. The mechanism of PDR includes protein-mediated resistance and RNA interference (RNAi). Both mechanisms have been shown to confer geminivirus resistance in transgenic tomato, common bean, cassava and others [14-18]. Here, we report the production of several JcMD-resistant J. curcus lines by expressing a hairpin double-stranded (ds) RNA targeting five key geminivirus DNA-A genes. Some of the transgenic lines displayed broad resistance to related geminiviruses, with $94.5 \%$ nucleotide identity in the transgene sequences.

\section{Results}

Hairpin, double-stranded RNA construct

We have previously identified the causal pathogen for the JcMD in Southern India as the strain of ICMV known as ICMV-Dha [3]. We chose the sequences of this ICMV-Dha strain to engineer virus resistance via RNAi technology. Three viral gene fragments were ligated to generate the sense and antisense arms in the hairpin dsRNA. Fragment $1(250 \mathrm{bp})$ targets the gene encoding $\mathrm{CP} / \mathrm{AV} 1$ and the $A C 5$ gene, fragment 2 (250 bp) targets genes for TrAP/AC2 and Ren/AC3 and fragment 3 (609 bp) targets genes for Rep/AC1 and AC4 (Figure 1A). The ligated fragment (fragment 1, 2 and 3) with the designated orientation as indicated by an arrow has the potential to generate a hairpin dsRNA structure with an intron (Figure 1B). The siRNA pool, produced from the hairpin (hp) RNA, should have the potential to silence five key viral genes encoding AC1 (Rep, Rep Replication associated protein), AC2 (TrAP, transcriptional activator protein), AC3 (Ren, (Replication enhancer protein), AV1 (Coat protein, CP) and AC4. We placed this hpRNA-encoding DNA fragment into a chemicalinducible marker excision vector which has been shown to function in J. curcus [13].

We then replaced the original G10-90 promoter with a Cauliflower mosaic virus (CaMV) 35S promoter with double enhancers and named it pX9-hpICMV RNAi. Upon chemical induction with $17 \beta$-estradiol, Cre/lox $P$ mediated recombination excised the DNA fragment containing the hygromycin-resistance gene. This recombination event resulted in placing the hpRNA-encoding DNA fragment immediately downstream of the $35 \mathrm{~S}$ promoter [13]. The PCR product using primer 1 and 2 should be approximately $6 \mathrm{~kb}$ before chemical induction and approximately $1.2 \mathrm{~kb}$ after induction. However, the approximately $6 \mathrm{~kb}$ product could not be amplified using our PCR program. The absence of PCR products using primer 3 and 4 indicated the excision of the hygromycin phosphotransferase $(H p t)$ gene (Figure $1 \mathrm{C}$ ).

\section{Plant transformation and virus inoculation}

The pX9-hpICMV RNAi vector was transformed into Agrobacterium and a total of 133 T0 transgenic plants were generated. We performed PCR analysis on genomic DNA using two pairs of primers (P1-P2 and P3-1 together with P4-1, Figure 1C). A total of 53 out of 133 plants showed a $1.2 \mathrm{~kb}$ product using primers $\mathrm{P} 1$ and $\mathrm{P} 2$, indicating the occurrence of successful marker excision. However, the presence of PCR products of P3-1 and P4-1 corresponding to the HPT gene suggested that all 53 transgenic plants were chimeric. Figure 2A shows the results of transgenic lines 1 to 54 . We purified the PCR products from the P1-P2 primer of line 13, 16, 19, $25,31,38,50,52$ and cloned into T-vector. DNA sequencing of these products confirmed the positive bands were true marker-free products (data not shown). Transgenic plants which were positive for P1-P2 products were 
A

B

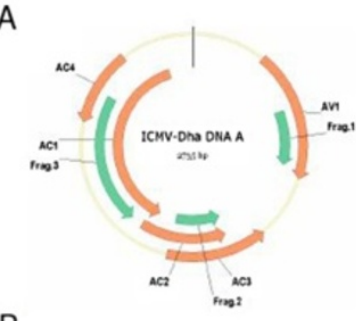

Frag.1 Frag.2, Frag.3

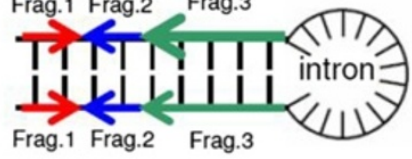

C

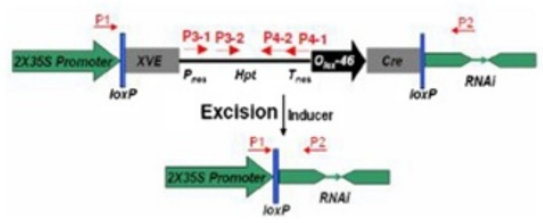

D

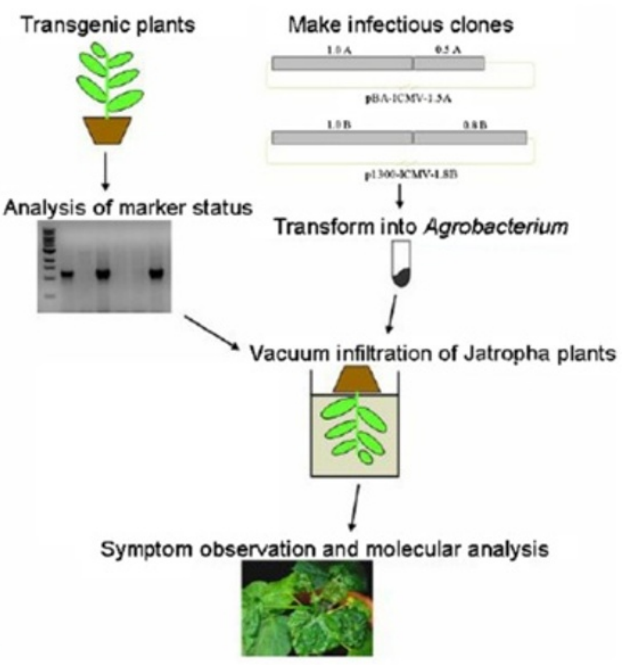

Figure 1 Schematic diagrams of the transformation vector and experimental procedure. (A) Selection of three DNA fragments targeting different viral genomic regions. (B) The three fragments were ligated and assembled into a sequence which, when transcribed, would produce a hairpin RNAi structure. Arrows indicate the orientation of each fragment in the hairpin structure. (C) Schematic diagram of the structural features of the inducible pX9- hplCMV RNAi construct and Cre/loxP-mediated DNA recombination (Zuo et al. Guo et al. [19,20]). Cre, the bacteriophage P1 Cre recombinase with an intron; Frag, fragment; Hpt, a hygromycin-resistance marker gene driven by nopaline synthase (nos) promoter (Pnos); ICMV, Indian cassava mosaic virus; loxP, specific recognition sites of Cre; OlexA-46, eight copies of the LexA DNA-binding site fused to the -46 CaMV 355 promoter; XVE, a chimeric transactivator containing the regulator domain of an estrogen receptor. Arrows inside transcription units indicate the direction of transcription. P1 to P4 denote primers used for PCR analysis to a detect recombination event for Hpt selection marker excision shown in Figure 2. (D) A flowchart of experimental procedure for screening virus resistance transgenic events by Agrobacterium-mediated infection.

used for virus challenge by vacuum infiltration with Agrobacterium-mediated virus infection (Figure 1D).

Two and a half months after the ICMV-Dha virus challenge, inoculated WT and susceptible transgenic plants showed very obvious curling and a mosaic phenotype on systemic leaves. We extracted genomic DNA and performed quantitative PCR to investigate virus titers in transgenic and WT plants. Uninfected WT plants were used as controls, and the average value of these control plants was set as 1 . There was no cycle threshold $(\mathrm{Ct})$ value difference between symptomless resistant transgenic plants and uninfected control plants. In total, 15 independent transgenic lines presented with the symptomless phenotype and no virus could be detected in these resistant transgenic plants. However, we detected very high virus titers in susceptible transgenic plants, which were similar to those found in infected WT plants (Figure 3). Six months after virus inoculation, the susceptible transgenic plants became obviously stunted with malformations and plant size reduction, whereas the resistant transgenic plants grew normally (Figure 4). The virus titers correlated very well with the severity of virus symptoms. A much lower virus amount was detected in plants with mild symptoms (for example line 65) compared with plants with strong symptoms (for example line 8) (Figure 3 and Figure 4D, E). We collected samples from the resistant T0 plants and performed PCR analysis to confirm the occurrence of a marker excision event (Figure 2B).

Next, we performed Southern blotting to examine the transgene copy number in resistant lines. As there are two EcoRV sites around the two loxP sites, the genomic DNAs were digested with EcoRV (Figure 5A). Southern blots using probe prepared from the $35 \mathrm{~S}$ promoter detected the copy number of the transgene irrespective of the marker status. Figure $5 \mathrm{~B}$ shows that resistant T0 plant lines 7, 20, 25, 50, 82, 113, 131 and 133 contained a single copy of the transgene. Along with quantitative PCR (qPCR) analysis of viral titers and symptomatic observations, we considered these transgenic plants to be candidate-positive resistant plants.

\section{Heritable virus resistance in T1 plants}

We chose number 82 as the first candidate for further characterization as two line $82 \mathrm{~T} 0$ plants (regenerated from a single transgenic event and confirmed by thermal asymmetric interlaced (TAIL)-PCR sequencing) showed a consistent virus resistance trait (Figure 4C). T1 seeds derived from $\mathrm{T} 0$ plant line 82 were germinated along 

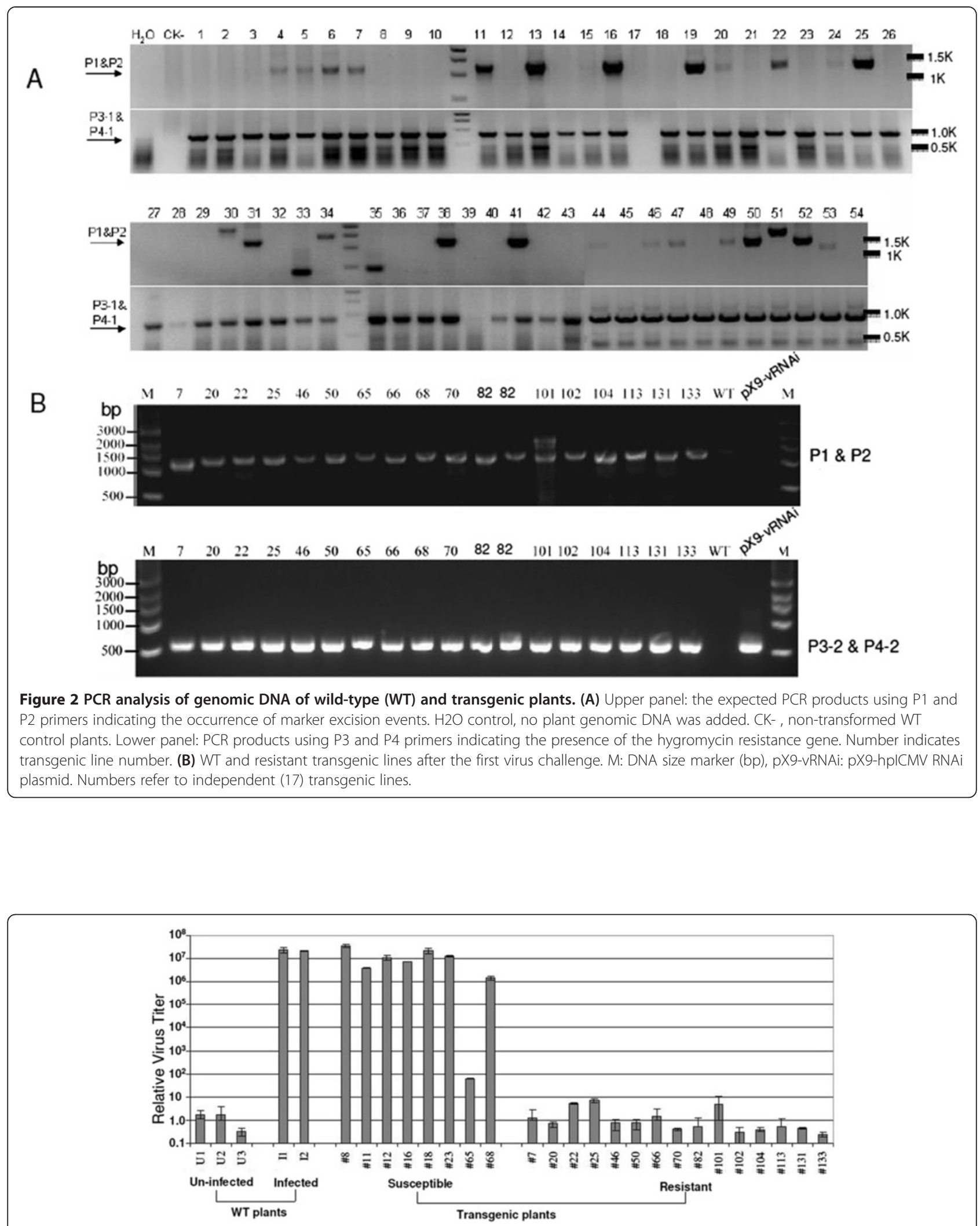

Figure 3 Quantitative PCR analysis of virus titer in WT and transgenic plants after the first virus challenge. Plants were inoculated with virus by vacuum infiltration. Uninfected WT plants were used as controls and the average control value was set as 1. I, infected WT plants; U, uninfected WT plants; WT, wild-type. 


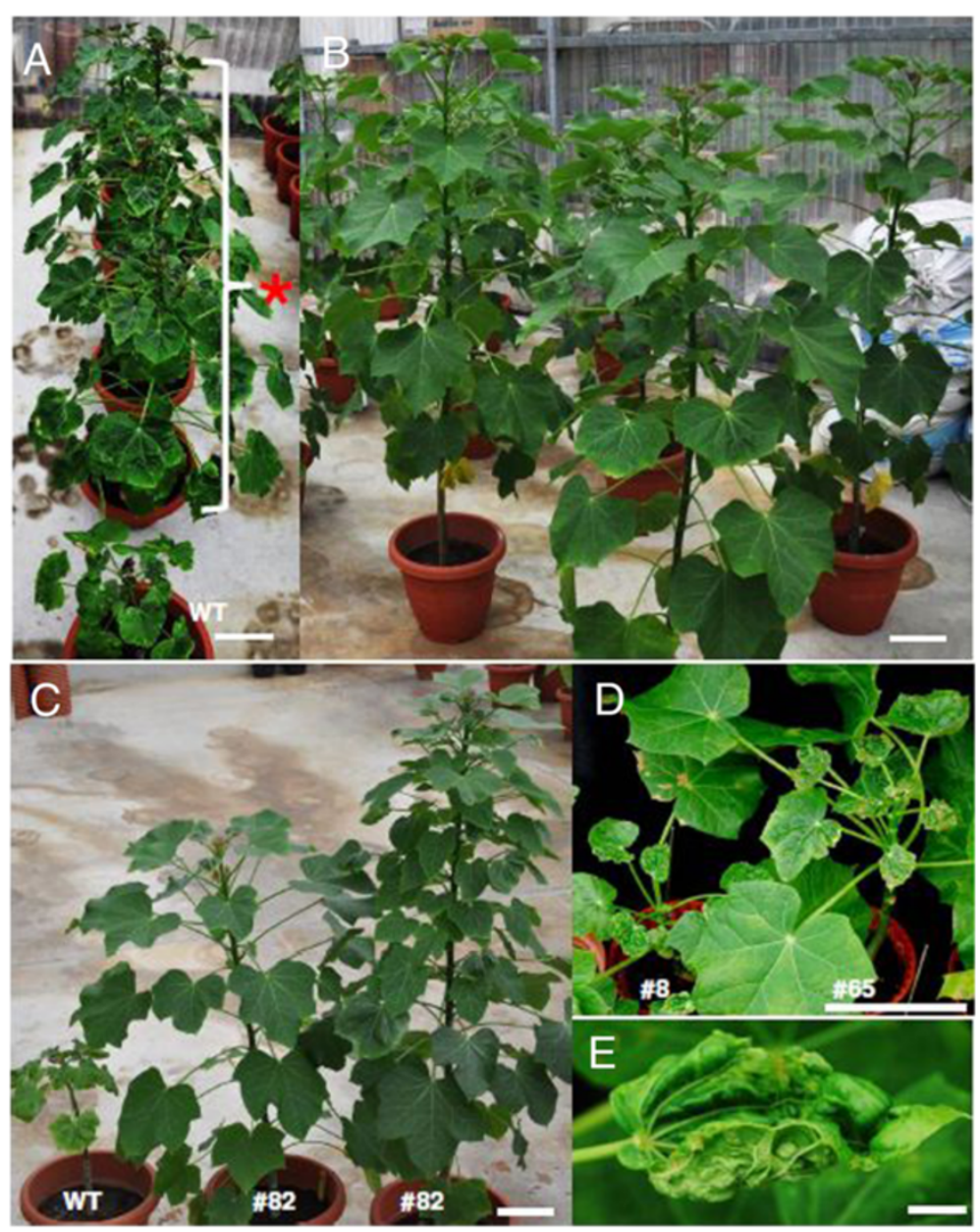

Figure 4 Symptoms of plants after the first virus challenge. Bar: $10 \mathrm{~cm}$ except $1 \mathrm{~cm}$ in (E). (A) WT and susceptible transgenic lines (indicated as ${ }^{*}$ ) with virus symptoms. (B) Putative resistant transgenic lines. (C) Comparison of infected WT and resistant transgenic lines. Left: infected WT plant with virus symptoms; middle and right: two T0 transgenic plants from the same transgenic event line 82 with virus resistance. (D) Two different lines with different severity of virus disease symptoms; severe line 8 and mild line 65. (E) Severe symptoms on leaf of line 8.

with the WT control. J. curcus plants with between three and four true leaves were inoculated with ICMV-Dha. Two months after the virus challenge, WT plants and transgenic line 82-3 showed very obvious virus disease symptoms, whereas transgenic plants $82-1$ and $82-2$ grew normally (like uninfected control plants) (Figure 6A). qPCR analysis showed the absence of detectable virus in transgenic plants $82-1$ and $82-2$, but high virus titers were obtained in line $82-3$ and WT plants (Figure 6B). To analyze the unexpected virus-sensitive phenotype in line 82-3 we performed PCR analysis and Southern blotting using genomic DNAs isolated from leaf samples taken before the virus challenge. We found that no band was amplified from both P1-P2 and P3-P4, indicating line 82-3 was likely a null segregant (Figure 6C). Southern blotting showed the same bands as T0 transgenic plants in lines $82-1$ and $82-2$, but no signal was detected for $82-3$, confirming it was indeed a null segregant (Figure 6D). Overall, our results show that transgenic plants based on the multitarget dsRNA approach can confer heritable resistance.

\section{Resistance to a second Indian cassava mosaic virus strain sharing $\mathbf{9 4 . 5 \%}$ nucleotide identity with ICMV-Dha}

We also tested whether the ICMV resistance conferred by hpRNAi has broad virus resistance. We recently reported a second ICMV isolate from the Singaporean Jatropha tree (named ICMV-SG, accession number [JX518289]), which shares $94.5 \%$ nt homology with the ICMV-Dha strain [7]. Before the virus challenge, we carried out PCR-based genotyping with primer pairs P1-P2 and P3-1, together with P4-1. We found a band of the expected size amplified from P1-P2, but not P3-1 and P4-1, from both lines 82-4 and $82-11$, indicating these two plants (82-4 and 82-11) might be marker-free plants, whereas line $82-14$ was likely a null segregant as was line 82-3 (Figure 7A). We tested plants of lines $82-4$ and $82-11$, along with six other plants 
A

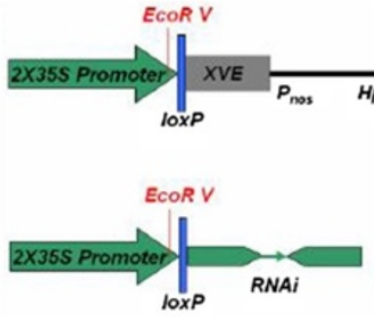

B

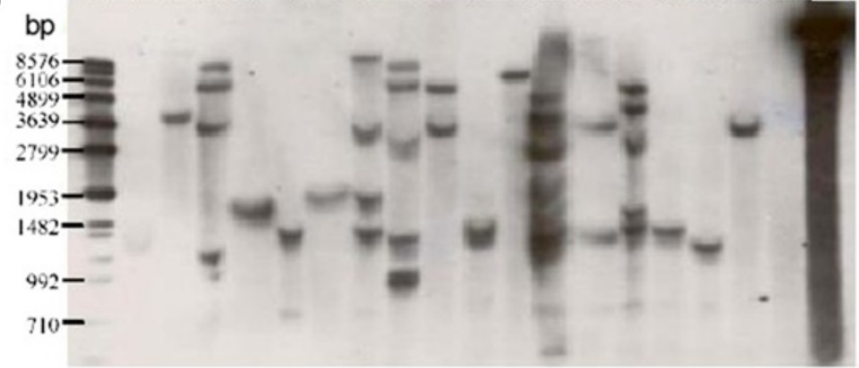

Figure 5 Analysis of transgene copy number by Southern blotting. (A) Schematic diagram of marker-free vector-based hairpin RNAi structure. (B) Southern blot using a probe carrying the CaMV 355 double enhancers. WT control or transgenic plant DNAs were digested with EcoRV. Probe prepared from the $35 \mathrm{~S}$ double enhancers detected the transgene copy number irrespective of the marker status. Cre, the bacteriophage P1 Cre recombinase with an intron; Frag, fragment; Hpt, a hygromycin-resistance marker gene driven by nopaline synthase (nos) promoter (Pnos); ICMV, Indian cassava mosaic virus; loxP, specific recognition sites of Cre; OlexA-46, eight copies of the LexA DNA-binding site fused to the -46 CaMV 355 promoter; $X V E$, a chimeric transactivator containing the regulator domain of an estrogen receptor. Arrows inside transcription units indicate the direction of transcription.

\section{A}
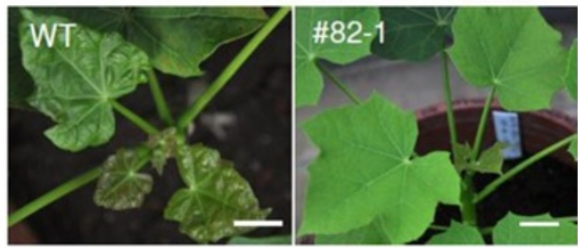

B

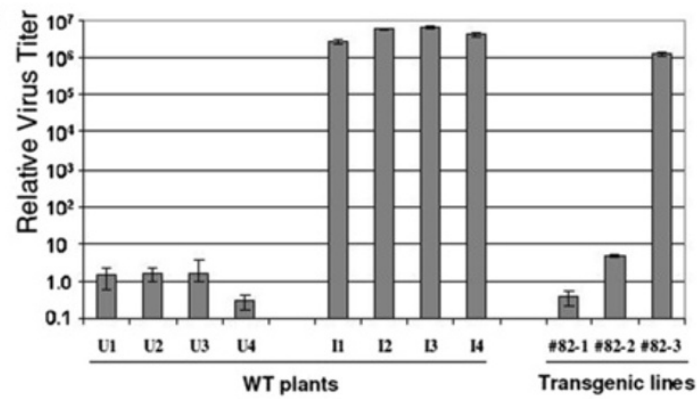

bp $\quad 82-182-282-3$ WT

C
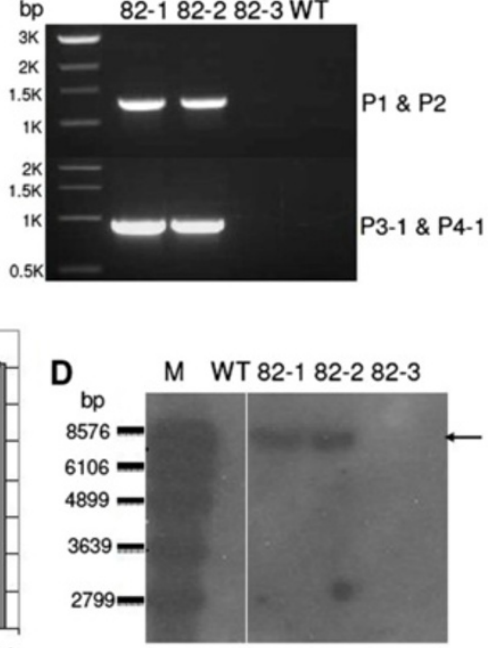

Figure 6 Heritable virus resistance trait in T1 transgenic plants. (A) Virus symptoms in WT control plants and progeny plants of transgenic line 82-1 after infection of ICMV-Dha. Bar: $1 \mathrm{~cm}$. (B) Quantitative PCR analysis of virus titers after virus challenge. Uninfected (U1 to U4) WT plants were used as controls and the average control value was set as 1. Inoculated (11 to 14) WT plants were used as positive controls. (C) PCR analysis of genomic DNAs prepared from WT and transgenic lines. Upper panel: PCR product using P1 and P2 primers. Lower panel: PCR product using P3-1 and P4-1 primers. (D) Southern blotting using a probe carrying the CaMV 355 double enhancers for transgenic T1 progeny plants derived from selfing of T0 plant 81. Note that line 82-3 was a null segregant.M: DNA size markers in bp. 


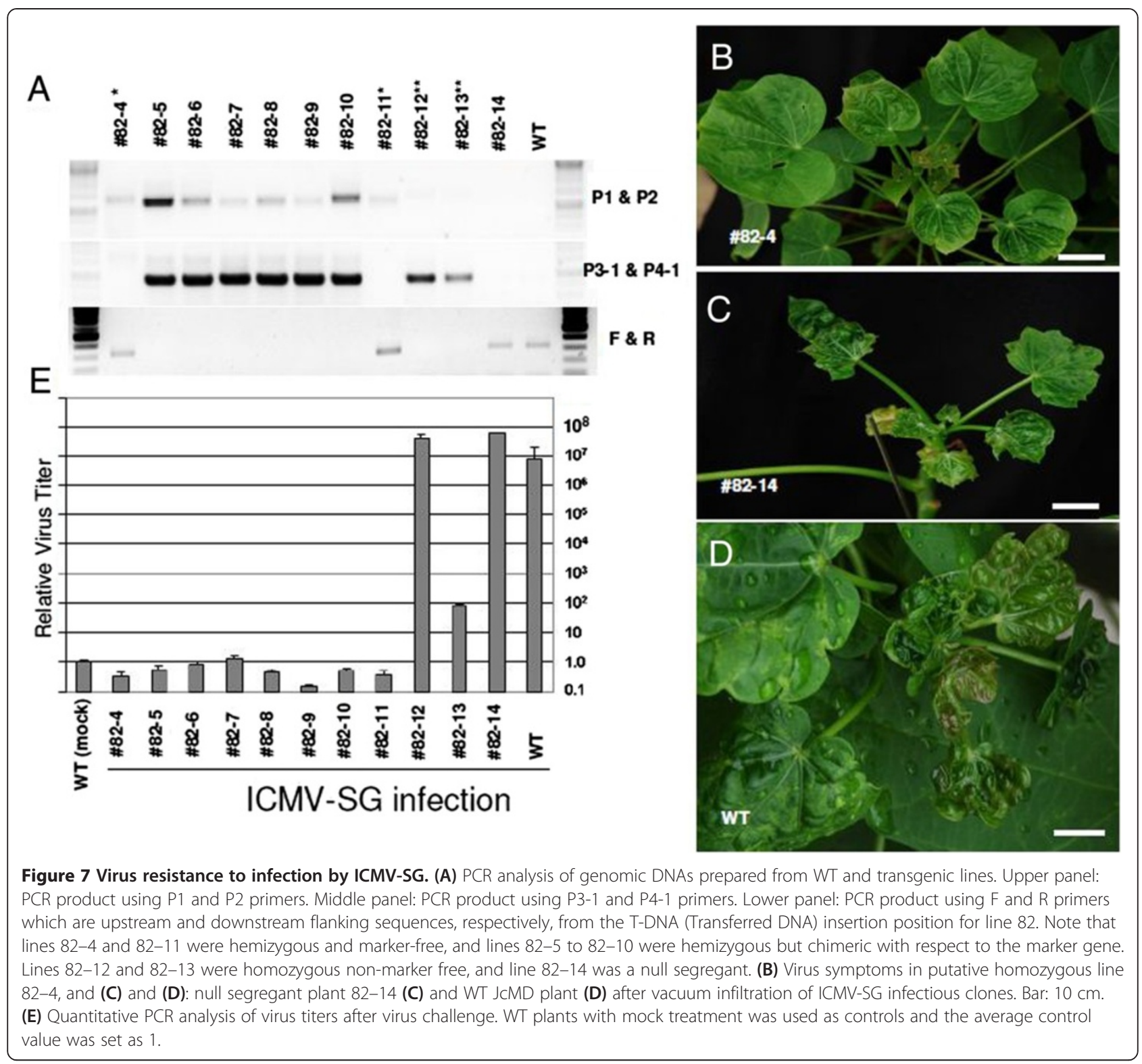

(lines $82-5$ to $82-10$ ), which were still chimeric with respect to the marker gene, for possible resistance to the second virus (ICMV-SG) using the agroinfection-based infection method. As expected, all of the seven plants in which marker excision had occurred were found to be resistant to ICMV-SG in the T1 generation. Further genotype analysis showed that all seven of these plants were hemizygous (lower panel of Figure 7A). The null segregant line 82-14 and two other plants which still retained the marker gene showed typical virus infection symptoms and accumulated high levels of virus genomic DNA, similar to WT control plants (Figure 7B,C,D,E).

We reasoned these ICMV-resistant plants should be also resistant to multiple ICMV strains within a similar evolution clade. Multiple sequence alignment of full-length
DNA-A was carried out using the ClustalV program Vector $\mathrm{NTI}^{\odot}$ (Life technologies, Carlsbad, United States) with default parameters. Phylogenetic trees were constructed from multiple alignments using the neighbor-joining method in the MEGA4 program [21], and a bootstrap analysis with 1,000 replicates was performed. Only values above 70 were reported on the trees (Figure 8). Based on the evolutionary phylogenetic tree we deduced that the resistant lines should also contain resistance to another two viral isolates recovered from J. curcus.

\section{Discussion}

During the last decade geminiviruses have emerged as one of the major causative pathogens of economically important crops such as cassava, cotton and tomato. As 


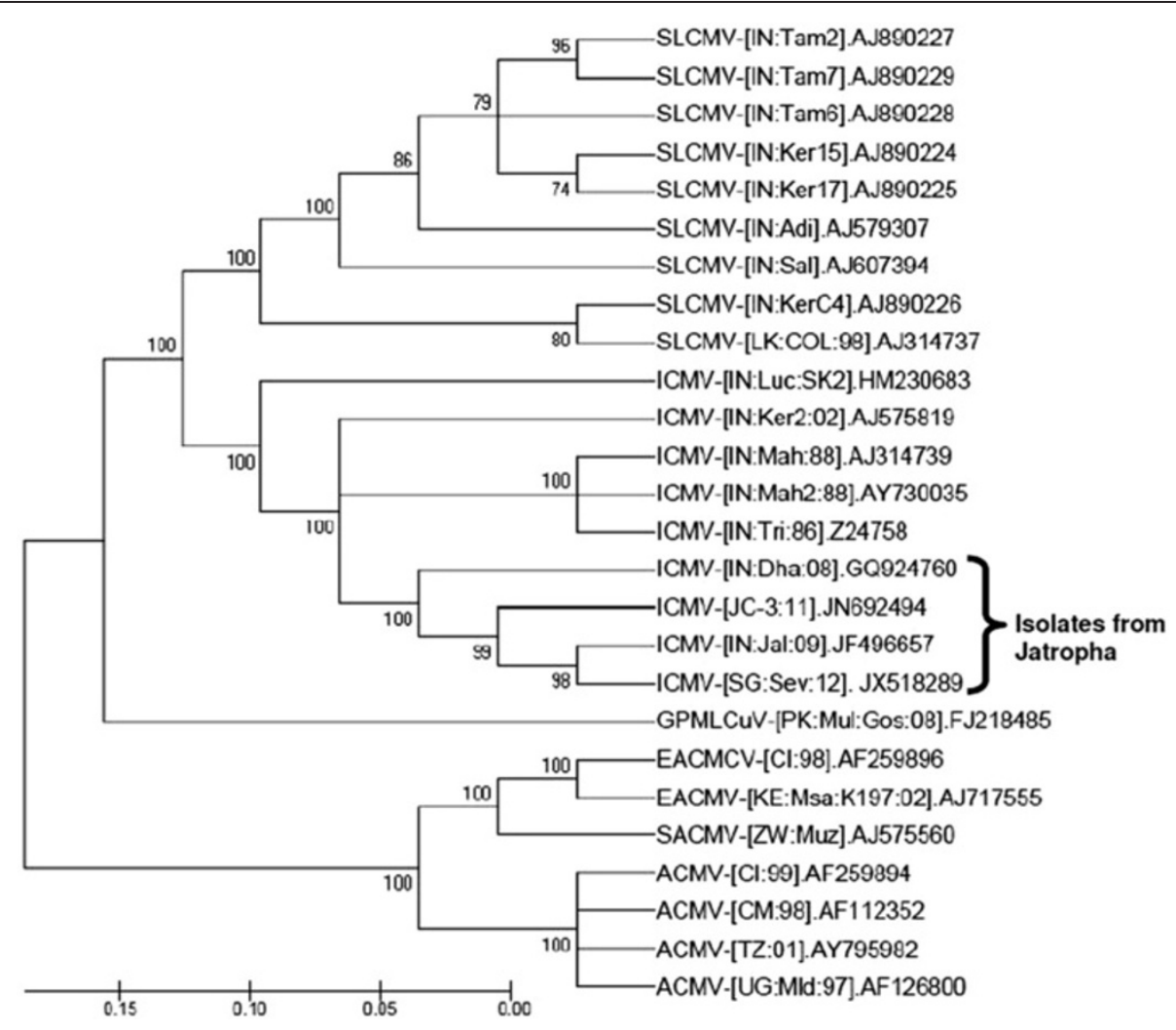

Figure 8 Phylogenetic relationship of viral isolates recovered from infected J. curcus plants. Four J. curcus-isolates formed one clade in a diagram showing the phylogenic relationship among various geminiviruses. Transgenic lines generated from this report are supposed to be resistant to geminiviruses from this clade. ACMV, African cassava mosaic virus; EACMCV, East African cassava mosaic Cameroon virus; EACMV, East African cassava mosaic virus; SACMV, South African cassava mosaic virus; ICMV, Indian cassava mosaic virus; SLCMV, Sri Lankan cassava mosaic virus; GPMLCUV, Gossypium punctatum mild leaf curl virus. The database accession number of each sequence is given.

resistance genes are not always available in the relevant crop germplasm, biotechnological approaches have been used to generate transgenic plants to confer virus resistance. Several different strategies have been reported to confer virus resistance to transgenic model plants by expression of: (1) trunked viral proteins, (2) artificial zinc finger nuclease, (3) peptide aptamers capable of binding to viral proteins, (4) non-pathogen-derived antiviral agents and so on [18,22-25]. However, successful applications of these strategies to generate virus-resistant crop plants are rare. In the case of RNA viruses, expression of virus-derived hpRNA has been shown to provide resistance in transgenic plants; more recently, this strategy has been shown to work for DNA viruses such as geminiviruses as well [26]. Successes have been reported with RNAi technology using either single or multiple viral gene sequences, or by artificial miRNA [27-29]. Single target gene approaches have first been used. For example, sequences targeting the $A C 1$ gene (which encodes the multifunctional Rep protein), the coat protein gene and $A C 4$ gene have been shown to confer geminivirus resistance in tomato, bean and tobacco plants [14-16,30-32]. In the case of the Chickpea chlorotic dwarf Pakistan virus
(CpCDPKV), a member of Mastrevirus (also a member of the Geminiviridae family) a multi-target approach was adopted. The RNAi trigger sequences include those encoding the $\mathrm{N}$-terminus of the Rep gene, the large intergenic (non-coding region; LIR) and the N-terminus of the movement protein gene [32]. Notably, the first field proven transgenic geminivirus-resistant plant-common bean (Phaseolus vulgaris) showed that the begomovirus Bean golden mosaic virus (BGMV) can also be suppressed by the expression of a hpRNA transgene derived from AC1 [33].

Here, we employed an RNAi strategy using hairpin dsRNA to silence five key viral genes of the ICMV. Five viral genes were chosen as targets: genes coding for $\mathrm{AC1}$, AC2, AC3, AV1and AC4. This multi-target strategy conferred transgenic J. curcus plants with high resistance to multiple virus infection. After two rounds of virus challenge, resistant plants were free of virus symptoms and no virus could be detected (Figures 4 and 6). Using qPCR to measure and quantify viral titers, we found strong virus resistance in the resistant transgenic lines as compared to WT and susceptible lines (Figures 3, 6 and 7). Our results, together with those of others [30-33], confirm that the hairpin dsRNA-mediated RNAi approach is indeed a 
promising technology in generating virus-resistant plants and/or conferring stable and effective resistance in plant crops.

An interesting feature of the work presented here is that we were able to challenge the transgenic plants with two distinct viruses $(94.5 \%$ nt identity for the whole DNA-A), thereby allowing us to ascertain resistance to related viruses. There is $95.3 \%$ nt identity between the ICMV-Dha and ICMV-SG strains if we include sequences that we used for the hpRNAi construction. Two other J. curcus-isolated ICMV strains, ICMV-JC3 and ICMV-Jalgon, share at least 95\% nt identity with the Dha strain sequences that we used for hpRNAi construction (Figure 8 and Additional file 1). In view of this high sequence homology we expect that the transgenic lines generated in this study may also be resistant to these two additional strains. Further field trials are necessary to ascertain whether the multi-target hpRNAi approach can indeed confer durable and heritable resistance to geminiviruses. Nevertheless, here we provide evidences that the multi-target hpRNAi strategy can confer resistance to the ICMV. There were several transgenic T0 lines showing virus resistance to the first ICMV-Dha infection, especially for the line 82 . A total of $10 \mathrm{~T} 1$ progeny transgenic plants derived from line 82 were free of virus symptoms with no detectable virus, whereas the null segregant $82-3$ was as sensitive as WT plants, when challenged with either ICMV-Dha or ICMV-SG strains (Figures 6 and 7). Lines 82-4 and 82-11 are good candidate plants for further commercial development since they are marker-free and contain only a single T-DNA insert. Taken together, our results support and reinforce the notion that the transgenic resistance trait is not only durable but also heritable.

\section{Conclusions}

We generated transgenic J. curcus plants with resistance to ICMV via expression of a hairpin dsRNA with sequences homologous to five key ICMV DNA-A genes. Virus resistance was confirmed through two rounds of inoculation with J. curcus-isolated strains of ICMV, ICMV-Dha and ICMV-SG. The T1 progeny transgenic plants were virus resistant, confirming that the resistance phenotype was heritable. Transgenic plants generated from this study can be used in various Jatropha breeding programs.

\section{Materials and methods} Plasmids construction

We replaced the G10-90 promoter in pX7-GFP [20] with a synthetic $35 \mathrm{~S}$ promoter harboring a double enhancer (detailed sequence in Additional file 2). The resulting vector was named as pX9-GFP. Three fragments of ICMVDha DNA-A (Genbank accession number [GQ924760]) were chosen as the target region. The ligated DNA fragment (fragment 1: 521-770 nt, fragment 2: 1210-1459 nt and fragment 3: 1671-2279 nt; see Figure 1B) was generated by two rounds of overlapping extension PCR using the following primers:

\section{F1-5: 5'AGCGCCTCGAGCGTTTGAATCTAGACA CGATGTGCTC-3, \\ F1-3: 5'-TGCAGTGATGAGTTCCCCTGTGCGTGA \\ ACATGTTAAACACCTCACCGAAATCCT-3, \\ F2-5: 5'-GATTTCGGTGAGGTGTTTAACATGTTCA \\ CGCACAGGGGAACTCATCACTGCAGC-3', \\ F2-3: 5'-GGAATGTTCCCCATTCCAAGGTATCGA \\ ATACCCTCAAGAAACGCCAGGTCTGAG-3', \\ F3-5: 5'-CAGACCTGGCGTTTCTTGAGGGTATTC \\ GATACCTTGGAATGGGGAACATTCCAG-3', \\ F3-3: 5'-AGCGCAAGCTTTAGCTGGAATTGGGCC \\ CTGGATTGCAGA-3'.}

Sequences for fragments 1, 2 and 3 were compared with those from related ICMV strains isolated from $J$. curcus (Additional file 1).

The PCR fragment was inserted in the sense orientation into the Xhol/HindIII sites of a pSKint vector [20] to generate pSK-int-sense ICMV. Another fragment, amplified with forward primer 5'AGCGCGAATTCTAGCTGGAA TTGGGCCCTGGATTGCAGA-3' and reverse primer 5'AGCGCACTAGTCGTTTGAATCTAGACAC-

GATGTGCTCCA-3', was subsequently placed in the antisense orientation into the EcoRI/SpeI sites of pSK-intsense ICMV to give pSK-int-ICMV RNAi. Finally, the entire RNAi cassette comprising the sense and antisense fragments joined by the Arabidopsis thaliana Actin II intron was excised from pSK-int using the flanking XhoI/ SpeI sites and inserted into the XhoI/SpeI site of pX9-GFP, yielding the construct pX9-hpICMV RNAi (pX9-vRNAi).

\section{Explant material for transformation}

Seeds were obtained from Jatropha curcas (JcMD) elite plants (JOil, Singapore) [34]. Cotyledons were harvested from seedlings between five and seven-days-old, cut into small pieces $(5 \times 5 \mathrm{~mm})$ and used as explants for transformation [13].

\section{PCR analysis of genomic DNA}

Genomic DNAs were prepared with DNeasy plant mini kits (Qiagen, Hilden, Germany) according to the manufacturer's instructions. Approximately $50 \mathrm{ng}$ of genomic DNA were used for PCR. The reactions were subjected to $94 \mathrm{C}$ for 30 seconds, $60^{\circ} \mathrm{C}$ for 30 seconds, and $72^{\circ} \mathrm{C}$ for 2 minutes for 40 cycles. Primers P1 (5'-ATCTCCACTGACGTAAGGGATGAC-3') and P2 (5'-GTTTAA GATCTACTTACGTAATCAAGC-3') were used to check the occurrence of marker excision events. DNA fragments containing the hygromycin resistance gene were amplified 
by either P3-1 (5'-GAGGGCGAAGAATCTCGTGCTTTC3') and P4-1 (5'-TACTTCTACACAGCCATCGGTCCA-3') or P3-2 (5'-GAAGAATCTCGTGCTTTCAG-3') and P4-2 (5'-CAACCAAGCTCTGATAGAGT-3'). The product amplified by primers P3-1 and P4-1 was 885 bp, whereas the product amplified by primers P3-2 and P4-2 was 745 bp (Figure 1C).

\section{Virus challenge assay}

Infectious clones of ICMV-Dha and ICMV-SG carrying tandem repeats of DNA-A and DNA-B were described [3,7]. Virus challenge assays were performed by Agrobacterium-mediated vacuum infiltration [35]. Plants were vacuum-infiltrated two times within a 10-day interval.

\section{Real-time PCR to detect viral titers in challenged plants}

Equal amounts of genomic DNA were used for analysis. Real-time PCR was performed with Power SYBR ${ }^{\mathrm{mi}}$ Green PCR Master mix (Applied Biosystems, Foster City, California, United States) and ran in ABI7900HT. Forward primer 5'-CTGCACAATGTGGGACCCTTTG-3' and reverse primer 5'-CTTCGCCCTGATGACAGAGATC-3' were used for the amplification of viral DNAA of either ICMV-Dha (128-290 nt) or ICMV-SG (127$289 \mathrm{nt})$. All samples were run in triplicate and the data was analyzed with RQ manager at a preset threshold cycle value (Applied Biosystems, Foster City, California, United States). The Jatropha curcas $r b c L$ DNA served as an internal control using forward primer 5'GGAGTTCCGCCTGAGGAAG-3' and reverse primer 5'-CTTCTCCAGCAACGGGCTC-3'. As described by Prisco et al. [36], the relative quantification of virus titers was determined based on the value of the $\mathrm{Ct}$, using the comparative $C_{T}$ method and the formula $2^{-\Delta \Delta C t}$.

\section{Southern blotting}

Genomic DNA was digested with restriction enzymes and separated on $0.8 \%$ agarose gels. The gels were processed and resolved DNA bands transferred to a nylon Hybond- $\mathrm{N}^{+}$membrane (GE Biosciences, Buckinghamshire, United Kingdom) following standard procedures [13]. Membranes were hybridized with a CaMV $2 \times 35 \mathrm{~S}$ promoter probe which included the double enhancers with 3' ends at -76 (A) of $35 \mathrm{~S}$ promoter. The probes were DIG-dUTP-labeled by PCR using a PCR DIG probe synthesis kit (Roche Shanghai, China) according to the manufacturer's instructions and signals were detected by autoradiography.

\section{Additional files}

Additional file 1: Figure S1. Alignments for the fragments (A: fragment 1, B: fragment 2, C: fragment 3) between ICMV-Dha and relative strains. *indicated ICMV strains identified from Jatropha.
Additional file 2: Sequence of the synthetic $35 \mathrm{~S}$ promoter harboring a double enhancer used in this report.

\section{Abbreviations}

ACMV: African cassava mosaic virus; Bp: base pair; CpCDPKV: Chickpea chlorotic dwarf Pakistan virus; CP: Coat protein; dsRNA: ds, Double-stranded RNA; EACMCV: East African cassava mosaic Cameroon virus; EACMV: East African cassava mosaic virus; hpRNA: Hairpin RNA; hpRNAi: Hairpin RNA-mediated RNAi; ICMV-Dha: Indian cassava mosaic virus Dha strain; ICMV-SG: Indian cassava mosaic virus SG strain; JCMD: Jatropha curcas mosaic disease; GPMLCuV: Gossypium punctatum mild leaf curl virus.kb, kilobases; PCR: polymerase chain reaction; PDR: Pathogen-derived resistance; qPCR: quantitative polymerase chain reaction; Rep: Rep Replication associated protein; RNAi: RNA interference; SACMV: South African cassava mosaic virus; siRNA: Small interfering RNA; SLCMV: Sri Lankan cassava mosaic virus; TAIL-PCR: Thermal asymmetric interlaced PCR; TrAP: transcriptional activator protein; Ren: Replication enhancer protein.

\section{Competing interests}

A patent relating to transgenic $J$. curcus with virus resistance has been filed by the Temasek Life Sciences Laboratory.

\section{Authors' contributions}

$J Y, J Q$ and NHC designed the experiments. JY, JQ, NEBR, CB and CW performed the vector construction, molecular analysis and virus challenge analysis. HZM did the J. curcus transformation. ZGM, CB and SYJ performed molecular analysis and Southern blot analysis. JY, JQ, NHC and NEBR analyzed the data and drafted the manuscript. All authors read and approved the final manuscript for publication.

\section{Acknowledgments}

We thank Drs Yan Hong and Chengxin Yi (JOils) for the J. curcus JcMD seeds and Mr Khar Meng Ng for his help in taking care of the plants. This work was supported by the Strategic Priority Research Program of the Chinese Academy of Sciences (grant number: XDB1 1040300), Temasek Life Sciences Laboratory and the Singapore Millennium Foundation.

\section{Author details}

'Temasek Life Sciences Laboratory, NO.1 Research Link, National University of Singapore, Singapore 117604, Singapore. ${ }^{2}$ State Key Laboratory of Plant Genomics, Institute of Microbiology, Chinese Academy of Sciences, NO.1 Beichen West Road, Beijing 100101, China. ${ }^{3}$ Laboratory of Plant Molecular Biology, Rockefeller University, 1230 York Avenue, New York, NY 10021, USA.

Received: 5 December 2013 Accepted: 25 September 2014

Published online: 21 October 2014

\section{References}

1. Raj SK, Snehi SK, Kumar S, Khan MS, Pathre U: First molecular identification of a begomovirus in India that is closely related to Cassava mosaic virus and causes mosaic and stunting of Jatropha curcas L. Australasian Plant Dis Notes 2008, 3:69-72.

2. Aswatha Narayana DS, Rangawarmy KT, Shankarappa KS, Maruthi MN, Reddy CNL, Rekha AR, Murthy KVK: Distinct begomoviruses closely related to Cassava Mosaic Viruses cause Indian Jatropha Mosaic Disease. Int I Virol 2007, 3:1-11.

3. Gao S, Qu J, Chua NH, Ye J: A new strain of Indian cassava mosaic virus causes a mosaic disease in the biodiesel crop Jatropha curcas. Arch Virol 2010, 155:607-612.

4. Shehi S, Srivastava A, Raj S: Biological characterization and complete genome sequence of a possible strain of Indian cassava mosaic virus from Jatropha curcas in India. J Phytopathol 2012, 160:547-553.

5. Ramkat RC, Calari A, Maghuly F, Laimer M: Biotechnological approaches to determine the impact of viruses in the energy crop plant Jatropha curcas. Virol J 2011, 8:386.

6. Kashina BD, Alegbejo MD, Banwo OO, Nielsen SL, Nicolaisen M: Molecular identification of a new begomovirus associated with mosaic disease of Jatropha curcas L. in Nigeria. Arch Virol 2013, 158:511-514. 
7. Wang G, Sun $Y, X u R$, Qu J, Tee C, Jiang X, Ye J: DNA-A of a highly pathogenic Indian cassava mosaic virus isolated from Jatropha curcas causes symptoms in Nicotiana benthamiana. Virus Genes 2014, 48:402-405.

8. Brown J, Fauquet C, Briddon R, Zerbini M, Moriones E, Navas-Castillo J: Geminiviridae. In Virus Taxonomy - Ninth Report of the International Committee on Taxonomy of Viruses. Edited by King A, Adams M, Carstens E, Lefkowitz E. London, Waltham, San Diego: Associated Press, Elsevier Inc; 2012:351-373.

9. Ahuja SL, Monga D, Dhayal LS: Genetics of resistance to cotton leaf curl disease in Gossypium hirsutum L. under field conditions. J Hered 2007, 98:79-83.

10. Li MR, Li HQ, Jiang HW, Pan XP, Wu GJ: Establishment of an Agrobacteriuim-mediated cotyledon disc transformation method for Jatropha curcas. Plant Cell Tiss Organ Cult 2008, 92:173-181.

11. Pan J, Fu Q, Xu Z: Agrobacterium tumefaciens-mediated transformation of biofuel plant Jatropha curcas using kanamycin selection. Afr J Biotechnol 2010, 9:6477-6481.

12. Kajikawa M, Morikawa K, Inoue M, Widyastuti U, Suharsono S, Yokota A, Akashi K: Establishment of bispyribac selection protocols for Agrobacterium tumefaciens-and Agrobacterium rhizogenes-mediated transformation of the oil seed plant Jatropha curcas L. (Special Issue: Jatropha research: a new frontier for biofuel development). Plant Biotechnol J 2012, 29:145-153.

13. Qu J, Mao HZ, Chen W, Gao SQ, Bai YN, Sun YW, Geng YF, Ye J: Development of marker-free transgenic Jatropha plants with increased levels of seed oleic acid. Biotechnol Biofuels 2012, 5:10.

14. Vanderschuren H, Alder A, Zhang P, Gruissem W: Dose-dependent RNAimediated geminivirus resistance in the tropical root crop cassava. Plant Mol Biol 2009, 70:265-272.

15. Bonfim K, Faria JC, Nogueira EO, Mendes EA, Aragao FJ: RNAi-mediated resistance to Bean golden mosaic virus in genetically engineered Ahuja (Phaseolus vulgaris). Mol Plant Microbe Interact 2007, 20:717-726.

16. Abhary MK, Anfoka GH, Nakhla MK, Maxwell DP: Post-transcriptional gene silencing in controlling viruses of the Tomato yellow leaf curl virus complex. Arch Virol 2006, 151:2349-2363.

17. Zhang P, Gruissem W: Efficient replication of cloned African cassava mosaic virus in cassava leaf disks. Virus Res 2003, 92:47-54.

18. Vanderschuren H, Stupak M, Futterer J, Gruissem W, Zhang P: Engineering resistance to geminiviruses-review and perspectives. Plant Biotechnol J 2007, 5:207-220.

19. Zuo JR, Niu QW, Møller SG, Chua NH: Chemical-regulated, site-specific DNA excision in transgenic plants. Nature Biotech 2001, 19:157-161.

20. Guo HS, Fei JF, Xie Q, Chua NH: A chemical-regulated inducible RNAi system in plants. Plant J 2003, 34:383-392.

21. Tamura K, Dudley J, Nei M, Kumar S: MEGA4: Molecular Evolutionary Genetics Analysis (MEGA) software version 4.0. Mol Biol Evol 2007, 24:1596-1599.

22. Chen W, Qian Y, Wu X, Sun Y, Wu X, Cheng X: Inhibiting replication of begomoviruses using artificial zinc finger nucleases that target viralconserved nucleotide motif. Virus Genes 2014, 48:494-501.

23. Shepherd DN, Mangwende T, Martin DP, Bezuidenhout M, Kloppers FJ, Carolissen $\mathrm{CH}$, Monjane AL, Rybicki EP, Thomson JA: Maize streak virusresistant transgenic maize: a first for Africa. Plant Biotechnol J 2007, 5:759-767.

24. Reyes MI, Nash TE, Dallas MM, Ascencio-lbanez JT, Hanley-Bowdoin L: Peptide aptamers that bind to geminivirus replication proteins confer a resistance phenotype to tomato yellow leaf curl virus and tomato mottle virus infection in tomato. J Virol 2013, 87:9691-9706.

25. Safarnejad MR, Fischer R, Commandeur U: Recombinant-antibodymediated resistance against Tomato yellow leaf curl virus in Nicotiana benthamiana. Arch Virol 2009, 154:457-467.

26. Bonas $U$, Lahaye $T$ : Plant disease resistance triggered by pathogenderived molecules: refined models of specific recognition. Curr Opin Microbiol 2002, 5:44-50.

27. Prins M, Laimer M, Noris E, Schubert J, Wassenegger M, Tepfer M: Strategies for antiviral resistance in transgenic plants. Mol Plant Pathol 2008, 9:73-83.

28. Vu TV, Choudhury NR, Mukherjee SK: Transgenic tomato plants expressing artificial microRNAs for silencing the pre-coat and coat proteins of a begomovirus, Tomato leaf curl New Delhi virus, show tolerance to virus infection. Virus Res 2013, 172:35-45.

29. Qu J, Ye J, Fang R: Artificial microRNA-mediated virus resistance in plants. J Virol 2007, 81:6690-6699.
30. Mubin M, Hussain M, Briddon RW, Mansoor S: Selection of target sequences as well as sequence identity determine the outcome of RNAi approach for resistance against cotton leaf curl geminivirus complex. Virol J 2011, 8:122

31. Ramesh SV, Mishra AK, Praveen S: Hairpin RNA-mediated strategies for silencing of tomato leaf curl virus AC1 and AC4 genes for effective resistance in plants. Oligonucleotides 2007, 17:251-257.

32. Nahid N, Amin I, Briddon RW, Mansoor S: RNA interference-based resistance against a legume mastrevirus. Virol J 2011, 8:499.

33. Aragao FJ, Faria JC: First transgenic geminivirus-resistant plant in the field. Nature Biotech 2009, 27:1086-1088.

34. Yi C, Zhang S, Liu X, Bui HT, Hong Y: Does epigenetic polymorphism contribute to phenotypic variances in Jatropha curcas L.? BMC Plant Biol 2010, 10:259.

35. Ye J, Qu J, Bui HT, Chua NH: Rapid analysis of Jatropha curcas gene functions by virus-induced gene silencing. Plant Biotechnol J 2009, 7:964-976.

36. Prisco GD, Zhang X, Pennacchio F, Caprio E, Li J, Evans JD, Degrandi-Hoffman G, Hamilton M, Chen YP: Dynamics of persistent and acute deformed wing virus infections in honey bees, Apis mellifera. Viruses 2011, 3:2425-2441.

doi:10.1186/s13068-014-0149-z

Cite this article as: Ye et al:: Engineering geminivirus resistance in

Jatropha curcus. Biotechnology for Biofuels 2014 7:149.

\section{Submit your next manuscript to BioMed Central and take full advantage of:}

- Convenient online submission

- Thorough peer review

- No space constraints or color figure charges

- Immediate publication on acceptance

- Inclusion in PubMed, CAS, Scopus and Google Scholar

- Research which is freely available for redistribution

Submit your manuscript at www.biomedcentral.com/submit
C) Biomed Central 